\title{
ANÁLISE INFANTIL: UMA ESTÓRIA DE HERÓIS
}

\author{
Daniele Fátima Oliveira* \\ Gilcinéia Rose da Silva Santos*
}

RESUMO: O presente artigo trata-se de uma revisão bibliográfica que objetiva associar a teoria psicanalítica e o brincar na prática clínica, para tanto utilizaremos recortes do atendimento de uma criança que expressa seus sentimentos por meio de uma história criada durante os atendimentos. Observou-se, nas sessões, o quanto se faz importante que o psicoterapeuta possibilite a expressão criativa do paciente na hora do brincar, entendendo que a criatividade da criança pode ser facilmente interrompida quando o terapeuta demonstra saber demais. Para que a psicoterapia obtenha bons resultados é necessária a espontaneidade da criança no setting terapêutico, ou seja, ela deve ser livre para conduzir o brincar à sua maneira.

PALAVRAS-CHAVE: Agressividade; Contos; Sublimação.

\section{CHILDREN'S ANALYSIS: A HERO STORY}

ABSTRACT: Current bibliographical review associates psychoanalytic theory and play in clinical practice. Cuttings of how a child expresses its feelings by means of a story invented during sessions are used. Results show the great importance that the psychotherapist triggers, during sessions, the patient's creativity during play. Children's creativity may be easily interrupted when the therapist tries to show she knows better. For good results, children's spontaneity within the therapeutic setting is highly relevant, or rather, the child is free to conduct play in its own manner.

KEY WORDS: Aggressiveness; Sublimation; Stories, .

\section{INTRODUÇÃO}

O presente artigo trata-se de um estudo teórico que tem por objetivo associar a teoria psicanalítica e o brincar na prática clínica. Utilizaremos recortes do

Psicóloga graduada pelo Centro Universitário de Maringá (UNICESUMAR), Brasil.

* Doutora em Psicologia pela Pontifícia Universidade Católica de São Paulo (PUCSP), Docente titular do Centro Universitário de Maringá (UNICESUMAR), Brasil; E-mail: gilcineia.santos@unicesumar.edu.br 
atendimento realizado em clínica-escola por uma estagiária do curso de psicologia.

O paciente é uma criança de sete anos de idade, e suas dificuldades nas sessões eram a resistência em falar sobre seus sentimentos, a agressividade e a teimosia. Durante as 28 sessões, a criança demonstrou preferência por atividades intelectualizadas e, dessa forma, decidiu iniciar uma história infantil em que poderia colocar seus próprios heróis, convidando a estagiária a escrevê-la enquanto o paciente ditava as palavras a serem usadas.

Klein (1981) articula que assim como as associações aos elementos dos sonhos levam às descobertas do conteúdo latente do mesmo, também os elementos do jogo da criança permitem uma visão de seu significado latente. E a análise do brincar, assim como a análise de adultos, ao tratar sistematicamente a situação presente como situação transferencial, e ao estabelecer suas conexões com a situação originalmente experimentada ou imaginada, dá à criança a possibilidade de liberar e elaborar a situação original da fantasia.

Desta forma, a história elaborada pelo paciente tornou-se um veículo importante para o acesso às suas fantasias latentes, ao criar oportunidades à estagiária de fazer interpretações significativas para o sucesso do tratamento.

Neste contexto é oportuno lembrar que em psicoterapia de orientação analítica é crucial ter em mente as diferentes formas de comunicação da criança de acordo com a idade, dadas suas condições motoras, perceptivas, cognitivas e de linguagem. Ainda, segundo Klein (1981), as crianças no período de latência apresentam dificuldades especiais na análise.

Comparadas aos adultos, seu ego ainda é pouco desenvolvido, não têm consciência de que estão doentes e não desejam ser curadas, de sorte que não possuem incentivos para iniciar análise e tampouco estímulo para prosseguir com ela. Os pacientes dessa idade não são fáceis de serem abordados pelo analista, pois não brincam como os pequeninos e nem fornecem associações verbais, como os adultos. Sendo assim, a psicoterapia de orientação psicanalítica bem como a psicanálise de crianças se valem da comunicação expressiva do terapeuta, que é, por excelência, a interpretação. 


\section{PSICODIAGNÓSTICO E O BRINCAR}

A avaliação diagnóstica, como também é denominado o psicodiagnóstico, é um período de significativa relevância terapêutica, porque implica na constituição de um espaço que permite por meio da relação do par terapêutico, um conhecimento global do paciente, e que, se realizado de forma adequada, respeitando os parâmetros teóricos e práticos, é tão terapêutico como é a própria terapia para o paciente (CARRASCO; POTTER, 2005). Além do mais, a avaliação psicológica agrega a coleta de informações que são analisadas e sintetizadas, criando a articulação entre a compreensão dos processos psíquicos e as situações-problemas, que determinam as ações e intervenções profissionais (LAZZARI; SCHMIDT, 2008 apud MILANI; MORAIS; OLIVEIRA, 2011).

$\mathrm{O}$ processo do psicodiagnóstico se faz presente no atendimento com crianças, no entanto o manejo teórico centra-se no brincar, pois é preciso lembrar que a brincadeira torna-se o instrumento de tradução da expressão infantil e o terapeuta deve fazer parte desse processo ao interagir com a criança. Nesse sentido, Arzeno (2003) descreve que

$\mathrm{Na}$ história da psicanálise um ponto muito controvertido foi o da legitimidade de equiparar ou não o brincar da criança com a livre associação e os sonhos dos adultos. Anna Freud considerou que isso não poderia ser feito, enquanto que outras psicanalistas de crianças, lideradas por Melanie Klein, sustentavam que sim e cada posição expunha as suas razões. Para Anna, o jogo é uma forma de acting que em nada pode ser comparado ao sonho ou às livres associações dos adultos. Para Klein, pioneira da sua utilização como técnica psicanalítica e em escrever os argumentos teóricos que sustentavam tal posição, é a via regia ao inconsciente, como o são os sonhos nos adultos. Para Anna Freud, a análise de crianças diferenciava-se enormemente da dos adultos por uma série de razões. A criança não possui consciência de doença, está ainda presa aos seus objetos originais, não sente prazer nenhum ao ser analisada, as resistências são intensas e explicáveis. Para Klein, pelo contrario, o brincar é a linguagem típica da criança. Quando falta a palavra o brincar expressa tudo, e mesmo quando a palavra já tiver sido incorporada, a linguagem lúdica é mais expressiva que a verbal ou, então, no mínimo, um complemento imprescindível. Afirma que a diferença existente entre a análise de adultos e a de crianças restringe-se a algumas questões técnicas como esta de brincar e interpretar a brincadeira ou o jogo da criança mais do que suas palavras. (ARZENO,2003, p 47) 
No período de latência, a criança começa a reprimir suas fantasias de forma mais severa do que nas fases anteriores. Klein (1981), diz que enquanto a criança pequena sofre influência imediata das experiências e fantasias instintivas, a criança do período de latência já as dessexualizou, assimilando-as de uma maneira diferente. Dessa forma, a criança passa a expressar suas fantasias masturbatórias de maneira dessexualizada, ou as reprime para atender as exigências de seu ego ou para agradar os pais, essa atitude é de extrema importância nesse período.

Os pacientes dessa faixa etária são bastante resistentes em entrar em contato consigo mesmo, é preciso que o ambiente terapêutico satisfaça de forma positiva a primeira impressão da criança a ser atendida. Zimerman (2009) discorre sobre a sala do terapeuta infantil dizendo que

A presença da caixa de brinquedos possibilita que a criança que ainda não tem satisfatórias condições de expressar-se verbalmente, ou que ainda está muito inibida, possa utilizar a linguagem por meio de montagens, desenhos, das histórias que cria e os papéis que ela confere aos personagens, a forma de brincar com os brinquedos e a utilização que as crianças menores empregam nas narrativas baseadas no "faz de conta...", aliás, uma excelente via para o conhecimento das fantasias. Cabe particularmente que os desenhos, modelagens e pinturas permitem perceber a força expressiva contida nas cores, nas proporções, nos limites que as figuras humanas desenhadas guardam em relação com o espaço do papel (que podem definir a importante discriminação de seus limites corporais, do seu "eu", em relação ao mundo exterior), etc. (ZIMERMAN, 2009).

Relacionado a essa aparente dificuldade do paciente verbalizar seus sentimentos, Castro e Stürmer, (2009) afirmam que

A criança e o adolescente, por estarem em transformações físicas e psíquicas, requerem de nossa mente flexibilidade e continência e um constante acesso ao nosso próprio material inconsciente, para dar conta dos fenômenos contratransferênciais que essas faixas etárias suscitam. Salientam a necessidade de atenção às formas comunicativas na sessão, que incluem, além da palavra, uma profusão de material não-verbal, que pode ser expresso por meio de jogos, desenhos, personificações, gestos, postura, mímica [...] pelas quais expressam suas fantasias e seus sentimentos, que exigem do psicoterapeuta uma grande capacidade negativa e paciência para lidar com o novo e o inusitado (2009, p.94) 
Dessa forma, a fase do psicodiagnóstico é de extrema importância para o bom andamento dos atendimentos, pois são nessas sessões iniciais que se estabelecerá o fator essencial da psicoterapia, ou seja, o vínculo da dupla terapêutica.

Como já dito acima, os recortes do caso que aqui serão citados como forma de exemplificar o manejo teórico e suas práticas, faz parte de um atendimento clínico de uma criança que de acordo com o desenvolvimento psicossexual deveria estar vivenciando o período de latência (7 anos). Durante o tratamento priorizou-se as teorias de Melanie Klein (1981), aliadas aos ensinamentos de Winnicott (1975), os quais sugeriam aos terapeutas infantis que valorizassem fundamentalmente o brincar, pois a brincadeira é mais importante do que sábias interpretações.

$\mathrm{O}$ autor sugere ainda que o psicoterapeuta possibilite a expressão criativa do paciente, entendendo que a criatividade da criança pode ser facilmente interrompida quando o terapeuta sabe demais e demonstra esse saber quando brinca. Para que a psicoterapia seja efetiva, o brincar precisa ser livre, espontâneo e não submisso (WINNICOTT, 1975 apud FORTESKI et al., 2014).

\subsection{RECORTES DO CASO F. E SUAS COMPREENSÕES.}

Os recortes apresentados para exemplificar o manejo técnico-teórico foram retirados das sessões conduzidas pelas autoras do presente artigo. O objetivo principal da apresentação desses recortes é fazer com que os leitores possam compartilhar da experiência que foi de grande valia para agregar conhecimento neste campo, possibilitando a compreensão do quanto à postura da estagiária contribuiu no desenvolvimento da criança em relação às queixas apresentadas.

O paciente em questão chegou à clínica-escola, conduzido por seus pais, tendo como queixa inicial: comportamentos agressivos, teimosia e medo do escuro. Filho caçula do casal, com dois irmãos, sendo que o mais velho não morava com a família nuclear, pois pertencia a outro núcleo familiar, tendo vínculo fraterno somente por parte do pai, dividia a atenção dos genitores com sua irmã do meio, sendo um relacionamento conflituoso por haver diferenças de idade e de interesses. $\mathrm{Na}$ época dos atendimentos ainda dormia na cama dos pais.

$\mathrm{Na}$ sétima sessão da fase do psicodiagnóstico, ficaram evidenciadas as necessidades de trabalhar com o paciente suas dificuldades em aceitar as frustrações 
relacionadas ao seu convívio com os pais, falar de seus sentimentos, bem como buscar o seu amadurecimento no tema mãe-filho, pois F. ainda permanecia fixado nas questões Edípicas. $O$ presente artigo não se trata de explicar essa fase, no entanto faz-se necessário retomar o complexo de Édipo para melhores entendimentos do caso. Sendo assim, segue o conceito apontado por Laplanche e Pontalis (1992) citado por Aragão (2014),

Conjunto organizado de desejos amorosos e hostis que a criança sente em relação aos pais. Sob a sua forma dita positiva, o complexo apresenta-se como na história de Édipo-Rei: desejo da morte do rival que é a personagem do mesmo sexo e desejo sexual pela personagem do sexo oposto. Sob a sua forma negativa, apresentase de modo inverso: amor pelo progenitor do mesmo sexo e ódio ciumento ao progenitor do sexo oposto. Na realidade, essas duas formas encontram-se em graus diversos na chamada forma completa do complexo de Édipo. Segundo Freud, o apogeu do complexo de Édipo é vivido entre os três e os cinco anos, durante a fase fálica; o seu declínio marca a entrada no período de latência. É revivido na puberdade e é superado com maior ou menor êxito num tipo especial de escolha de objeto. O complexo de Édipo desempenha papel fundamental na estruturação da personalidade e na orientação do desejo humano. Para os psicanalistas, ele é o principal eixo de referência da psicopatologia. (p. 77)

Após a fase do psicodiagnóstico, o paciente retorna aos atendimentos no ano seguinte para dar início à psicoterapia na clínica escola; ele estava com sete anos de idade no período dos atendimentos. Nas primeiras sessões preferiu os brinquedos não estruturados e atividades intelectualizadas e aparentemente tinha a necessidade de demonstrar sua inteligência para a estagiária. No decorrer das sessões, foi possível inferir que intelectualizar era o seu mecanismo de defesa para fugir das questões que o desagradava, ou seja, todas às vezes que o brincar trazia lembranças às quais o paciente não queria entrar em contato, ele iniciava brincadeiras que envolviam explicações complexas e se ocupava ensinando a estagiária a seu modo.

Nesse sentido, Safra (1996) aponta a importância da relação do sujeito com o símbolo que emerge no Setting. Trata-se de um símbolo que constitui o self, que cura, que o move para o contínuo "vir a ser". O autor diz ainda que a interpretação verbal só deve ser utilizada a partir do momento em que o analisando toma, deliberadamente, a sua produção como um elemento de comunicação para o 
analista. Tornar o inconsciente consciente, mas sem invadir o tempo e a capacidade criadora do paciente.

$\mathrm{Na}$ décima sessão de psicoterapia, o paciente decidiu iniciar uma história de super-heróis, onde projetou e sublimou a sua agressividade e seus conteúdos sexuais nos personagens. Passou a escrever em todas as sessões, concluindo seu conto duas semanas antes do término da terapia.

Tal como proposto por Bettelheim (2002), também compreendemos que as produções de F. fluem da necessidade de entender o que está se passando dentro do seu eu inconsciente. A criança adequa o conteúdo inconsciente às fantasias conscientes, o que a capacita a lidar com este conteúdo. É aqui que os contos de fadas têm valor inigualável e oferecem novas dimensões à imaginação da criança que ela não poderia descobrir verdadeiramente por si só. Ainda mais importante: a forma e a estrutura dos contos de fadas sugerem imagens à criança com as quais ela pode estruturar seus devaneios e com eles dar melhor direção à sua vida.

Durante as sessões que o paciente desenvolvia sua história, foi possível fazer interpretações que foram cruciais para a melhora dos sintomas inicialmente apresentados pelos pais. De acordo com Sousa e Abuchaim (1994), "interpretar é atribuir um significado novo ou diferente a algo aparente ou fenomênico, fazendo emergir algo que é oculto e imanente ao aparente ou fenomênico" (p. 227).

Segundo Klein (1981, p. 50),

$\mathrm{O}$ analista não deve temer fazer uma interpretação em profundidade, mesmo no principio da analise, já que o material pertinente às camadas mais profundas do psiquismo tornará a aflorar para ser elaborado mais tarde. A função da interpretação em profundidade é simplesmente a de abrir a porta do inconsciente e diminuir a angústia suscitada, preparando, assim, o caminho para o trabalho analítico.

As interpretações realizadas durante os atendimentos possibilitaram que $\mathrm{F}$. pudesse tomar consciência dos seus comportamentos, mesmo sendo criança e não verbalizando o entendimento sobre os fatos era possível verificar o seu progresso na terapia e no relato dos pais. Desta forma, os atendimentos foram concluídos ao fim da $28^{a}$ sessão com a entrevista final com progenitores de F. para fazer os apontamentos necessários sobre sua evolução na terapia. 
Sendo assim, segue abaixo o recorte do conto elaborado pelo paciente, as interpretações feitas pela estagiária e o nítido progresso nas verbalizações e entendimento do paciente sobre si.

\subsubsection{Conto e interpretações}

$\mathrm{Na}$ décima sessão de psicoterapia o paciente começou a pensar na história que iria contar e pediu à estagiária que desenhasse os personagens que seriam os heróis, enquanto ele desenharia os inimigos. F. desenhou vários personagens para serem os vilões, tais como: A Mão Esmagadora, O Agudo, O Machado de Guerra, entre outros. Ele criou de forma linear, traçou a ideia e desenvolveu sem interrupções, dando a impressão de que tudo já estava construído em sua cabeça.

Os desenhos são excelentes meios de ativação de associações e de expressão infantil. Para Trinca $(1987$, p. 3), é fato notório que na psicoterapia, as crianças se comunicam através do desenho, é o meio de contato entre elas e psicoterapeutas, tendo um valor funcional e substituindo a linguagem oral (TRINCA, 1987).

Ainda segundo Trinca (2003), o desenho desperta conteúdos internos e permite a observação dos movimentos emocionais, sendo um campo de investigação e de expressão compartilhadas pela criança, auxiliando a compreensão de seu estado emocional.

Após a ilustração dos personagens, o paciente solicitou à estagiária que redigisse a estória enquanto ele narrava.

Segue abaixo o conto "Os Heróis do Caribe"

O Super $S$ estava indo para o mercado, quando ele escutou um pedido de socorro, então, ele chamou a super Vaca, a sua fiel ajudante. Daí ele foi ver, e era a Mão Esmagadora, ela estava esmagando a cidade inteira, mas o Super $S$ não pode deixar, pegou a sua espada e gritou: Eu não vou deixar você esmagar a cidade, se você quiser esmagar a cidade passe por mim primeiro. A mão disse: Seu desejo é uma ordem, e correu para cima dele. A Super Vaca percebeu que ele ia ser esmagado, então ela correu também; quando ela chegou perto dele a Vaca deu um pulo e espetou a Mão Esmagadora, mas era um alarme falso; quando ele espetou, um buraco se abriu e começou a 
vazar ar, então o Super S falou: Ué, era de borracha com engrenagem preta! Acho que alguém controla.

O Machado de guerra foi ver o que estava acontecendo com a mão esmagadora feita de engrenagem preta e controlação, porque tinha caído o sinal da câmera que ele tinha instalado na Mão Esmagadora. Ele viu a mão esmagadora deitada no chão com um furo dos grandes, então, o Machado de Guerra deu de cara com a Super Vaca e falou: Eu não vou deixar que você faça isso, o Super $S$ disse pra mim ficar de vigia, você não vai levar a Mão Esmagadora para o seu esconderijo secreto dos maus. O Super S disse pra mim dar uma chifrada em quem aparecer por aqui que seja mau. Então a Super Vaca correu para cima dele, mas antes dela chegar ele gritou de pavor e correu para o seu esconderijo. Chegando lá, a Água Viva Queimadora, que é a super Vilã muito poderosa, disse: Cadê a Mão Esmagadora? Então o Machado de Guerra disse: A Super Vaca estava lá e ela disse que ia dar uma chifrada em mim, então corri de pavor pra cá. Então a Água Viva pegou um pedaço de ferro e relou nele dizendo: Prisão, então ela pegou um pedaço de vidro e disse: Chave para a prisão, então ela colocou o Machado de Guerra dentro da prisão e jogou a chave num buraco sem fundo [sic].

Após o desenvolvimento da primeira parte da história, F. assimilou cada personagem com um membro de sua família, como segue no recorte abaixo:

E: F. quais pessoas que você conhece poderiam fazer esses personagens?

F: Qualquer pessoa?

E: Sim, quem poderia ser a Mão Esmagadora?

F: Meu pai

E: Por que você escolheu ele para ser a Mão Esmagadora?

F: Por causa da força dele

E: E quem seria o Machado de Guerra?

F: A minha irmã L., porque ele é muito estressado igual a ela

E: Quem seria a Água viva queimadora?

F: A minha vizinha, porque ela tem o poder de transformar quase tudo em raiva, ela e o marido brigam muito, quando eu vou lá fazer visita vejo eles brigando bastante.

E: E a Super Vaca, quem pode ser?

F: A minha mãe, porque a boca é igual à dela. A Super Vaca só sabe falar e transformar os chifres. A minha mãe transforma os cabelos em rabo de cavalo. (A mãe do paciente era cabeleireira)

E: E o Super $\mathrm{S}$ quem é?

F: Esse você já sabe

E: Não sei, não... Me diz quem é! 
F: É você, porque é super amigo do contador de histórias

E: E você ainda não entrou na história?

F: Vou entrar na semana que vem, eu vou ser o inimigo Espetossauro.

Essa primeira parte é uma prévia do que vamos encontrar no decorrer de toda a história, aparecem conteúdos sexualizados e agressivos que se repetem ao longo do conto.

Primeiramente será exposto o personagem da Mão Esmagadora; este se apresenta na história sempre destruindo tudo que tem pela frente. $\mathrm{O}$ paciente revela que esse personagem poderia ser o seu pai por causa da força. É preciso levar em consideração o conteúdo manifesto apresentado, no qual a Mão Esmagadora representa a agressividade do pai frente ao filho, onde na sua história F. pode descontar toda a sua raiva utilizando recursos para destruí-lo. Para isso, cria o personagem Super $S$ que pode suprir os seus impulsos do Id, a destruição de um pai mau. Quando perguntado ao paciente quem seria este Super Herói, ele responde que seria a estagiária, ou seja, ele foge da responsabilidade de punir esse pai e permite-se passar essa tarefa para o seu ego substituto, livrando-se da culpa.

Após a interpretação realizada a respeito de o paciente dormir na cama dos pais, em que foi apontado a F. o que acreditamos ser um desejo de ocupar o lugar do pai na cama, ele parou definitivamente de cometer esse ato quando sentia medo. Fica evidente no trecho abaixo do conto, a perturbação do paciente frente à relação de seus pais, o ciúme que sente da mãe e a raiva que sente do pai.

Ele viu a Mão Esmagadora deitada no chão com um furo dos grandes, então, o Machado de Guerra deu de cara com a Super Vaca e falou: "Eu não vou deixar que você faça isso, o Super S disse pra mim ficar de vigia, você não vai levar a Mão Esmagadora para o seu esconderijo secreto dos maus. O Super S disse pra mim dar uma chifrada em quem aparecer por aqui que seja mau" [sic].

O esconderijo secreto dos maus pode ser interpretado como o quarto de seus pais, onde acontece o coito do casal. $\mathrm{O}$ paciente pareceu expressar sua aversão em ver os pais juntos, estar de vigia nada mais é do que demonstrar seu desejo inconsciente de tomar o lugar de seu pai na cama. Por muitas vezes, em sua história, e até mesmo em suas atividades, apareceram personagens e objetos fálicos, tais como os chifres da supervaca, o machado de guerra, o Agudo e seu brinquedo 
preferido: a espada. Em outro trecho do conto, o paciente mais uma vez faz menção ao coito dos pais.

Então o Vibora Chefão disse: "Vai quebrar mais pedras, e ele foi... As pedras eram quebradas para o mau, para o vilão $\mathrm{ZZ}$ colocar dentro dele e entregar para a nuvem de chuva, para fazer chover pedra nas pessoas. Daí o Agudo estava quebrando mais e mais pedras e a nuvem de chuva ia crescendo e crescendo e jogando as pedras nos outros. Então as pessoas começaram a gritar: "Socorro, Super Heróis". Então o Super Sinal apareceu no céu e disse: "Está chovendo pedra, venham e tragam o Mega Polvo". Todos foram, até o Olverine e o Homem Inseto. Mas o único que dava conta disso era o Mega Polvo e o Sol Ardente. [sic]

A narração citada acima nos faz crer que se trata da vontade inconsciente do paciente em tomar posse do corpo da mãe por meio da copulação com ela. Faz menção sobre o crescer da nuvem que pode estar ligada com as suas fantasias que envolvem a concepção.

Klein (1981, p, 317) diz que

No menino a onipotência dos excrementos e pensamentos centraliza-se na onipotência do pênis, que substitui em parte a dos excrementos. Em sua imaginação, ele dota o próprio pênis de poderes destrutivos, assemelhando-o a bestas ferozes e vorazes e a armas mortíferas. A crença de que sua urina é uma substância perigosa e a equação de suas fezes deste último o órgão executor de suas tendências sádicas.

De acordo com a história e os relatos do paciente nas sessões, foi possível verificar que o personagem da Supervaca representaria a sua mãe, pois cuida do Super S, não deixando que a Mão Esmagadora (o pai) faça mal a ele. E o protege também do Machado de Guerra que F. diz ser sua irmã. A água Viva Queimadora faz o papel de um superego muito rígido, punitivo.

Chegando lá a Água Viva Queimadora que é a super Vilã muito poderosa, disse: "Cadê a Mão Esmagadora?" Então o Machado de Guerra disse: "A Super Vaca estava lá e ela disse que ia dar uma chifrada em mim, então corri de pavor pra cá". [...]Então o Machado de Guerra tentou usar suas lâminas laterais para cortar a prisão, mas a Água Viva Queimadora disse assim: "As grades são impenetráveis". [sic] 
O paciente demonstrava não conviver bem com seus próprios erros e tinha dificuldades em falar de si, fato que deixou transparecer no trecho que diz que as grades são impenetráveis, ou seja, inconscientemente estava dizendo à estagiária que não revelaria seus sentimentos com facilidade.

Ao longo de sua história, surgem vários heróis e vilões, mas F. manteve o foco principal naqueles que comparou com os seus pais. Encontrou na escrita uma forma de comunicar os seus conflitos internos.

Em seu trabalho, Curando com Histórias, Safra (2011) considera as diversas formas de jogo da criança, assim como as histórias, não só como um modo de encontrar expressão para desejos inconscientes, mas fundamentalmente como um modo de colocar seus conflitos subordinados à sua criatividade, ou seja, sob o domínio do eu. Acreditamos assim como o autor, ser imprescindível tal forma de expressão para o desenvolvimento cognitivo, ao lado do enriquecimento da apercepção criativa.

\section{CONCLUSÕES}

O brincar tornou-se a ferramenta principal e as atividades infantis ajudaram muito a adquirir a confiança do paciente em seus relacionamentos, com isso ele passou a desenvolver atividades projetivas que lhe davam a oportunidade de falar sobre seus problemas. Foi possível fazer interpretações significativas que o ajudaram na elaboração de muitos conteúdos que o incomodavam, tais como: ter medo do escuro, dormir com seus pais e intolerância à frustração.

Elaborar uma estória fez com que F. desenvolvesse a comunicação daquilo que o incomodava, a partir do crescimento e fortalecimento dos aspectos fragilizados do paciente, o rompimento do vínculo ocorreu de forma natural, visto que o paciente entendeu que o término do tratamento se deu em virtude de sua visível melhora.

\section{REFERÊNCIAS}

ABUCHAIM, S. R.; SOUSA, P. L. R. Rotas psicanalíticas. Pelotas: Educat.1994

ABERASTURY, A. A criança e seus jogos. 2. ed. Porto Alegre: Artmed, 1992. 
ARZENO, M. E. G. Psicodiagnóstico clínico. Porto Alegre: Artes Médicas, 2003.

ARAGÃO, M. S. S. (Org.). II Congresso Nacional de Literatura. João Pessoa: Mídia, 2014.

BETTELHEIM. B. A psicanálise dos contos de fadas. 16. ed. [s.l.]: Paz e Terra, 2002.

CARRASCO, L.K.; POTTER, J.R. Psicodiagnóstico: recurso de compreensão. In: MACEDO, M. M. K.; CARRASCO, L. K. (Org.). (Con)textos de entrevista: olhares diversos sobre a interação humana. São Paulo: Casa do Psicólogo, 2005.

CASTRO, M. G. K.; STÜRMER, A. Crianças e adolescentes em psicoterapia: abordagem psicanalítica. Porto Alegre: Artmed, 2009.

EIZIRIK, C.L.; AGUIAR, R.W.; SCHESTATSKY, S. S. (Org.). Psicoterapia de orientação analítica: fundamentos teóricos e clínicos. 3. ed. Porto Alegre: Artmed, 2014.

FORTESKI, R.; BORGES, C.D.; MOREIRA, B.B.; SEVEGNANI, G.R. Três abordagens em psicoterapia infantil. Revista Cesumar Ciências Humanas e Sociais Aplicadas, v.19, n.2, p. 525-544, jul./dez. 2014. Disponível em: < periodicos.unicesumar.edu. br/index.php/revcesumar/article/download/3223/2453 > . Acesso em: 21 fev. 2017.

FREUD. S. Notas sobre um caso de neurose obsessiva. Obras Psicológicas Completas. v. X, 1909. p. 168.

MILANI, R.G.; MORAIS, I.C.; OLIVEIRA, F.S. Psicodiagnóstico clínico com adolescentes: algumas contribuições. In: ENCONTRO INTERNACIONAL DE PRODUÇÃO CIENTÍFICA CESUMAR, 7., 2011, Maringá. Anais... Maringá: Cesumar, 2011.

KLEIN. M. Psicanálise da criança. 3. ed. São Paulo: Mestre Jou. 1981. p. 50.

SAFRA, G. O trabalho não verbal na análise de crianças. Espaço-Criança-Escritos Psicanalíticos, São Paulo, v. 2, n. 1, p. 25-29, 1996. 
SAFRA, G. Curando com histórias: a inclusão de pais na consulta terapêutica das crianças. 2. ed. São Paulo: Sobornost, 2011. v. 1. p.98.

TRINCA, W. Investigação clínica da personalidade: o desenho livre como estímulo de apercepção temática. 2. ed. São Paulo: EPU. 1987.

TRINCA, A. M. T. A intervenção terapêutica breve e a pré-cirúrgica infantil. São Paulo: Vetor, 2003.

ZIMERMAN, D. E. Manual de técnica psicanalítica: uma re-visão. Porto Alegre: Artmed, 2009.

Recebido em: 22 de fevereiro de 2017 Aceito em: 14 de abril de 2017 